\title{
Ceramic TiC/a:C protective nanocomposite coatings: Structure and composition versus mechanical properties and tribology
}

\author{
Nikolett Oláh ${ }^{\text {a,*, }}$ Zsolt Fogarassy ${ }^{\mathrm{a}}$, Attila Sulyok ${ }^{\mathrm{a}}$, János Szívós ${ }^{\mathrm{a}}$, Tamás Csanádi ${ }^{\mathrm{b}}$, \\ Katalin Balázsi ${ }^{a}$ \\ a Thin Film Physics Department, Institute for Technical Physics and Materials Science, Centre for Energy Research, Hungarian Academy of Sciences, \\ Konkoly-Thege M. Str. 29-33, 1121 Budapest, Hungary \\ b Institute for Materials Research, Slovak Academy of Sciences, Watsonova 47, 04001 Kosice, Slovakia
}

\section{A R T I C L E I N F O}

\section{Article history:}

Received 24 February 2016

Received in revised form

26 April 2016

Accepted 27 April 2016

\section{Keywords:}

$\mathrm{TiC} / \mathrm{a}: \mathrm{C}$ thin film

TEM

Tribology

Mechanical properties

XPS

\begin{abstract}
A B S T R A C T
The relationship between the structure, elemental composition, mechanical and tribological properties of $\mathrm{TiC} /$ amorphous carbon $(\mathrm{TiC} / \mathrm{a}: \mathrm{C}$ ) nanocomposite thin films was investigated. $\mathrm{TiC} / \mathrm{a}: \mathrm{C}$ thin film of different compositions were sputtered by DC magnetron sputtering at room temperature. In order to prepare the thin films with various morphology only the sputtering power of Ti source was modified besides constant power of $C$ source. The elemental composition of the deposited films and structural investigations confirmed the inverse changes of the a: $\mathrm{C}$ and titanium carbide (TiC) phases. The thickness of the amorphous carbon matrix decreased from $10 \mathrm{~nm}$ to $1-2 \mathrm{~nm}$ simultaneously with the increasing Ti content from 6 at\% to 47 at\%. The highest hardness (H) of $\sim 26 \mathrm{GPa}$ and modulus of elasticity (E) of $\sim 220 \mathrm{GPa}$ with friction coefficient of 0.268 was observed in case of the film prepared at $\sim 38 \mathrm{at} \% \mathrm{Ti}$ content which consisted of $4-10 \mathrm{~nm}$ width TiC columns separated by $2-3 \mathrm{~nm}$ thin a:C layers. The H3/E2 ratio was $\sim 0.4 \mathrm{GPa}$ that predicts high resistance to plastic deformation of the TiC based nanocomposites beside excellent wear-resistant properties $(\mathrm{H} / \mathrm{E}=0.12)$.
\end{abstract}

(c) 2016 Elsevier Ltd and Techna Group S.r.l. All rights reserved.

\section{Introduction}

The high hardness, elastic modulus and low friction coefficient are crucial to the development of different coatings for fundamental, industrial or medical applications. Nowadays, using different nanocomposite coatings in order to improve the aforementioned properties is wide spread. Therefore, nanocrystalline titanium carbide-, nitride-, carbonitride embedded in amorphous hydrogenated $(\mathrm{a}: \mathrm{C}-\mathrm{H})$ or un-hydrogenated $(\mathrm{a}: \mathrm{C})$ carbon matrix is a versatile material combining the superior properties of hard nanocrystallites and soft amorphous carbon matrix [1-5]. The TiC phase is suitable for lowering deformation and it can enhance the hardness of coatings. These types of nanocomposites show good hardness values if the crystal size is sufficiently small and the soft second phase, which has a so-called self-lubricant property, helps blocking crack propagation [6-8]. The mechanical and tribological properties also depend on grain/grain boundary microstructure and grain size refinement can be manipulated by sputtering power (element composition) [9] or by parameters of the deposition plasma (ion flux) [10] and by temperature. Thus, there are a

\footnotetext{
* Corresponding author.

E-mail address: olah.nikolett@energia.mta.hu (N. Oláh).
}

number of techniques to create titanium carbide. Selective laser melting of $\mathrm{TiC}$ is an excellent reinforcement candidate in aluminum matrix composites $[11,12]$. Dispersed $\mathrm{TiC}$ in the $\mathrm{Al}_{2} \mathrm{O}_{3}$ ceramic matrix (as substrate of magnetic heads and cutting tool) was applied as well by high energy ball milling followed by spark plasma sintering (SPS) process [13]. Fabricating of TiC-SiC nanocomposites by SPS of porous TiC scaffolds infiltrated with a SiC precursor by a sol-gel route leads to fully dense $\mathrm{TiC}-\mathrm{SiC}$ composites with uniform nanostructure [14]. Furthermore, Li et al. [15] and Liu et al. [16] investigated the structural and electronic properties of TiC (110) surfaces and the interface structure (adhesion and bonding character) of TiC/Ti by the first-principle density functional plane-wave pseudopotential calculation. The calculated results of the interfacial Ti-Ti bond have strong metallic and weak covalent character; meanwhile, a strong polar covalent interaction between the Ti-C was identified. Similar results to Wang Li et al. [15] were calculated by R. Ahuja et al. [17] based on the density functional theory.

However, the most widely used sputter deposition techniques for fabricating $\mathrm{TiC} / \mathrm{a}: \mathrm{C}(-\mathrm{H})$ nanocomposite thin films are the chemical vapor deposition (CVD) or the physical vapor deposition (PVD) and the various types of these methods as non-reactive magnetron sputtering [18], radio frequency (RF) sputtering [19,20], hybrid Ionized Physical Vapor Deposition/Plasma Enhanced Chemical Vapor Deposition process (IPVD/PECVD) [21] and direct 
current (DC) magnetron sputtering. For example, TiC(Ag)/a:C-H nanocomposite coatings with different $\mathrm{Ag}$ concentrations were fabricated by a magnetron sputter deposition system intended for the space and aircraft applications [22]. Mg-TiC nanocomposites of various volume fractions were also synthesized using disintegrated melt deposition technique followed by hot extrusion intended for structural and biomedical applications [23].

The aim of work was the investigation of the relationship between the exact elemental composition and mechanical and tribological properties of the $\mathrm{TiC} / \mathrm{a}: \mathrm{C}$ thin films prepared by $\mathrm{DC}$ magnetron sputtering at different deposition parameters. The compositions of the coatings are modified by changing the power of the titanium source between $5 \mathrm{~W}$ and $70 \mathrm{~W}$ besides a constant power of the carbon source $(150 \mathrm{~W})$ during the depositions. In the literature, the deposition temperatures are mostly around $200{ }^{\circ} \mathrm{C}$ $[20,24,25]$. In this work, the used deposition temperature was room temperature mostly for economic reasons and because it may be preferable for easier production in terms of the further applications for industry.

\section{Experimental procedures}

$\mathrm{TiC} / \mathrm{a}: \mathrm{C}$ thin films were deposited by DC magnetron sputtering. The detailed preparation steps of the coatings were described in our previous works $[26,27]$. In the current study, different samples were examined depending on the power of the titanium source $(5-70 \mathrm{~W})$ at fixed $150 \mathrm{~W}$ of carbon source power (Table 1). The films were sputtered at room temperature from two sources, a carbon target (99.999\%) and a titanium target (99.995\%). Both $2^{\prime \prime}$ targets originate from Kurt and Lesker Co. The thickness of the coatings was controlled by the deposition time between 30 and 25 min resulting in $\sim 102 \mathrm{~nm}$ to $\sim 180 \mathrm{~nm}$ thicknesses depending on titanium content. Namely, as the titanium deposition rate is increased, the time was reduced for the creation of roughly the same thickness films. All thin films were deposited onto roughly the same size of oxidized Si substrates having $300 \mathrm{~nm}$ thick amorphous oxide layer on the top. Thus, the structure of the thin films was investigated by Transmission Electron Microscopy (TEM) with different magnifications using a Philips CM-20 operated at $200 \mathrm{kV}$ accelerating voltage. Selection Area Electron Diffraction (SAED) was used for the phase analysis.

On the one hand, the elemental composition of the thin films was measured by Energy Dispersive Spectroscopy (EDS) using LEO 1540 XB digital, special (Gemini) Scanning Electron Microscope (FEG SEM). On the other hand, the average chemical composition of the films was examined by X-ray Photoelectron Spectroscopy (XPS) using an $\mathrm{Al}$ anode. The $5 \mathrm{~mm} \times 5 \mathrm{~mm}$ sized specimens were mounted onto a larger $\mathrm{Si}$ wafer and were introduced to the chamber for analysis. The oxide layer was removed from the film surface by argon ion sputtering in order to detect the internal composition of the films. In order to limit the possible damage of the top surface of the films $1 \mathrm{keV} \mathrm{Ar}$ ion beam at an $80^{\circ}$ angle of incidence was used. The XPS spectra were obtained using special CMA (Cylindrical Mirror Analyzer) with retarding field (type DESA 105 made by Staib Instruments Ltd) and the ion beam was scanned to such an extent that it sputtered the whole surface of the specimen evenly. Constant $1.5 \mathrm{eV}$ energy resolution was applied for all measurements. Composition was determined from the main XPS lines of the constituents as follows: C-1s at $284.4 \mathrm{eV}$, Ti-2p 1/ $2+3 / 2$ at $454.0 \mathrm{eV}, \mathrm{O}-1 \mathrm{~s}$ at $530.0 \mathrm{eV}$ and $\mathrm{Ar}-2 \mathrm{p}$ at $242 \mathrm{eV}$. While the original surface was stable during the measurement, the sputtered surface was found to be active, slowly accumulating graphite type carbon from the vacuum environment. Special attention was given for the proper sputtering conditions to avoid the surface contamination.

The mechanical characteristics of the TiC/a:C thin films were investigated by nanoindentation technique. The nanohardness $(\mathrm{H})$ and elastic modulus (E) of the nanocomposite coatings were measured by a Nanoindenter Agilent G200 (USA) device with a Berkovich diamond indenter at room temperature. Visibly clear areas were selected for indent preparation and $4 \times 4$ indents were performed on each sample. Prior to the indentation the tip was calibrated on a fused silica reference sample resulting reliable data from the depth of $\sim 20-40 \mathrm{~nm}$. It is important to note that the measured hardness values belonging to the depth range of $10 \%$ depth of total film's thickness corresponds indeed to the coating properties but the elastic modulus is most probably influenced by the substrate effect. Continuous stiffness measurement (CSM) mode with depth limit of $500 \mathrm{~nm}$ was applied for continuous registration of load, displacement and stiffness to determine the coating properties and to separate the effect of the substrate. Depth control mode was used during CSM method with standard frequency (f), amplitude (A) and loading rate $\left(\varepsilon^{*}\right)$ of $f=45 \mathrm{~Hz}$, $A=2 \mathrm{~nm}$ and strain rate of target $=0.051 / \mathrm{s}$, respectively. The Young's modulus and Poisson's ratio parameters of diamond tip used were $\mathrm{E}_{\text {tip }}=1141 \mathrm{GPa}$ and $\nu_{\text {tip }}=0.07$, respectively. The hardness and the indentation modulus values were automatically calculated according to the measuring standards based on the work of Oliver and Pharr [28]. Visibly aberrant data were neglected from the averaging. More details about the applied CSM method and the evaluation process can be found elsewhere [28,29].

The tribological behavior of the films was investigated by a ball-on-disk tester (CSM tribometer) moving on circular trajectory at room temperature. The sliding velocity was $0.05 \mathrm{~m} / \mathrm{s}$ under a normal load of $2 \mathrm{~N}$ using a $\mathrm{Si}_{3} \mathrm{~N}_{4}$ ball of $5 \mathrm{~mm}$ in diameter as the abrasive material with 3000 cycle under the air atmosphere at relative humidity $(\mathrm{RH})$ of $44 \%$ or $53 \%$.

\section{Results and discussion}

Fig. 1 shows the cross-sectional TEM investigations of deposited films. The detailed parameters for the coating thickness, diameter and thickness of the $\mathrm{TiC}$ nanocrystallite measured from TEM images are shown in Table 2 illustrate the inverse changes well which takes place in the morphology of the films at different compositions depending on the Ti target power. As the titanium content increased the amorphous carbon content decreased with the accumulation of TiC crystallites. The amorphous carbon has not gone through a graphitization process. In case of the first image (Fig. 1a) with the lowest Ti content ( $\sim 6$ at\% Ti), the amorphous structure dominates; in the $102 \pm 11 \mathrm{~nm}$ thick film, no nanocrystals were detected. As the titanium content increased, the

Table 1

The detailed deposition parameters of the $\mathrm{TiC} / \mathrm{a}: \mathrm{C}$ thin films.

\begin{tabular}{|c|c|c|c|c|c|c|c|c|c|c|c|c|c|}
\hline $\mathrm{P}_{\mathrm{Ti}}(\mathrm{W})$ & 5 & 10 & 15 & 20 & 25 & 30 & 35 & 40 & 45 & 50 & 55 & 60 & 70 \\
\hline $\mathrm{P}_{\mathrm{C}}(\mathrm{W})$ & 150 & 150 & 150 & 150 & 150 & 150 & 150 & 150 & 150 & 150 & 150 & 150 & 150 \\
\hline $\mathrm{t}(\min )$ & 30 & 30 & 30 & 30 & 30 & 30 & 30 & 30 & 28 & 28 & 28 & 25 & 25 \\
\hline Deposition rate of $C(\AA / s)$ & 0.3 & 0.3 & 0.3 & 0.3 & 0.3 & 0.3 & 0.3 & 0.3 & 0.3 & 0.3 & 0.3 & 0.3 & 0.3 \\
\hline Deposition rate of $\mathrm{Ti}(\AA / \mathrm{s})$ & 0.08 & 0.16 & 0.24 & 0.32 & 0.4 & 0.48 & 0.56 & 0.64 & 0.72 & 0.8 & 0.88 & 0.96 & 1.12 \\
\hline
\end{tabular}




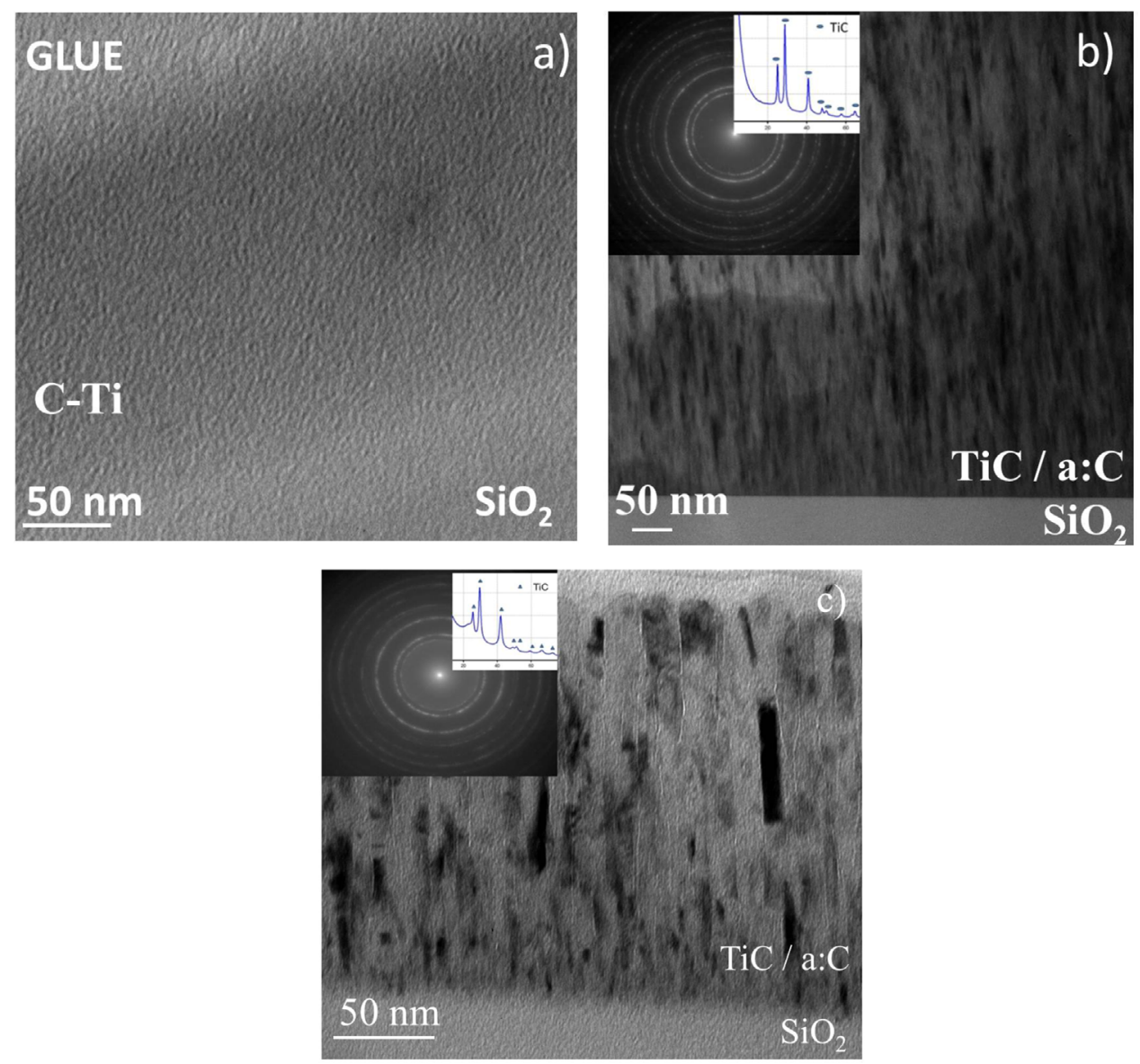

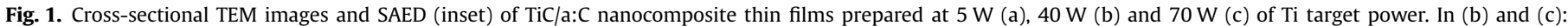
electron diffraction of fcc TiC nanocrystals with 111, 200, 220, 311, 222, 400 and 331 indices.

Table 2

Data from the cross-sectional TEM images for the coating thickness, diameter and thickness of the TiC nanocrystallite as function of Ti power and sputtering time at room temperature in argon (0.25 $\mathrm{Pa})$ atmosphere.

\begin{tabular}{rllll}
\hline $\begin{array}{l}\mathrm{P}_{\mathrm{Ti}}(\mathrm{W}) \\
\text { ness }(\mathrm{nm})\end{array}$ & $\begin{array}{l}\text { Coating thick- } \\
\text { TiC }\end{array}$ & $\begin{array}{l}\text { Morphology of } \\
\text { particles }(\mathrm{nm})\end{array}$ & $\begin{array}{l}\text { Thickness of TiC } \\
\text { columns (nm) }\end{array}$ \\
\hline 5 & $102 \pm 11$ & globular & 0 & - \\
10 & $105 \pm 2$ & & 0 & - \\
15 & $96 \pm 2$ & & $0.5-1$ & - \\
20 & $121 \pm 5$ & & $\sim 1$ & - \\
25 & $135 \pm 6$ & columnar & - & $1-2$ \\
30 & $113 \pm 4$ & & - & $2-6$ \\
35 & $153 \pm 6$ & & - & $4-8$ \\
40 & $137 \pm 5$ & & - & $4-10$ \\
45 & $144 \pm 2$ & & - & $6-17$ \\
50 & $158 \pm 7$ & & - & $9-16$ \\
55 & $146 \pm 2$ & & - & $14-19$ \\
60 & $152 \pm 5$ & & - & $10-21$ \\
70 & $180 \pm 12$ & & - & $10-26$ \\
\hline
\end{tabular}

nanocolumnar structure is observed as it can be seen in the second cross-sectional TEM image (Fig. 1b) prepared at $40 \mathrm{~W}$ of Ti target power $(\sim 38$ at\% Ti). Here the $137+5 \mathrm{~nm}$ thick film contains 4 $10 \mathrm{~nm}$ width TiC crystallites separated by $2-3 \mathrm{~nm}$ thin a:C. The TiC phase have already been identified from $15 \mathrm{~W}(\sim 18$ at\% $\mathrm{Ti})$ as given in the Table 2 . In addition, the presence of the face-centeredcubic (fcc) TiC nanocrystals was confirmed and a little (111) texture is assumed according to the SAED in cases of the second and the third cross-sectional TEM images (Fig. $1 \mathrm{~b}$ and c). Fig. 1c is a typical cross-sectional TEM image of a sample prepared at $70 \mathrm{~W}$ of Ti target power ( $\sim 47$ at $\% \mathrm{Ti})$. Here, the columns are separated by
1-2 $\mathrm{nm}$ a:C consist of $10-26 \mathrm{~nm}$ diameter TiC crystallites extending through the whole $180 \pm 12 \mathrm{~nm}$ thick layer. Overall, the thickness of amorphous carbon matrix decreases from $10 \mathrm{~nm}$ to $1-$ $2 \mathrm{~nm}$ and the size of the nanocrystals increased from $\sim 0.5 \mathrm{~nm}$ to $26 \mathrm{~nm}$ together with the Ti content.

The estimated data for the coating thickness, diameter and thickness of the TiC nanocrystallites (Table 2) are measured according to the cross-sectional TEM images.

Similarly to the TEM analysis, the opposite change of the a:C and carbide phases was also proved by the results of the XPS and EDS (Fig. 2a). The Ti content of the TiC/a:C thin films determined by EDS, XPS and the unbound (=amorphous) $C$ are summarized in Fig. 2a as functions of the Ti target power. On the other hand, the comparison of the total amount of $C$ by XPS and by EDS depending on the Ti target power is illustrated in Fig. 2b. The results of XPS, EDS and TEM are in a good agreement compared to the wellknown equilibrium macro C-Ti phase diagram [30]. Namely, even at the lowest total concentration of C $(52.7 \pm 7$ at\% by XPS and $64.5 \pm 5$ at\% by EDS) with the highest concentration of $\mathrm{Ti}$ ( $47.3 \pm 5$ at\% by XPS and $35.5 \pm 2$ at\% by EDS) no other Ti phase was detected out of $\mathrm{TiC}$. In our case the amorphous carbon was detected at room temperature. The difference between the results of XPS and EDS can be explained by the difficulties of the C analysis. Both measurements could cause some carbon accumulation.

The first relevant change was observed in the case of the film prepared at $40 \mathrm{~W}$ of Ti target power (Fig. 1b) wherein the characteristic element composition was $\sim 38$ at\% Ti and $\sim 60$ at $\%$ C, based on the XPS measurement. The nanocolumnar structure formation has begun. Till now, the atomic percent of the bound 

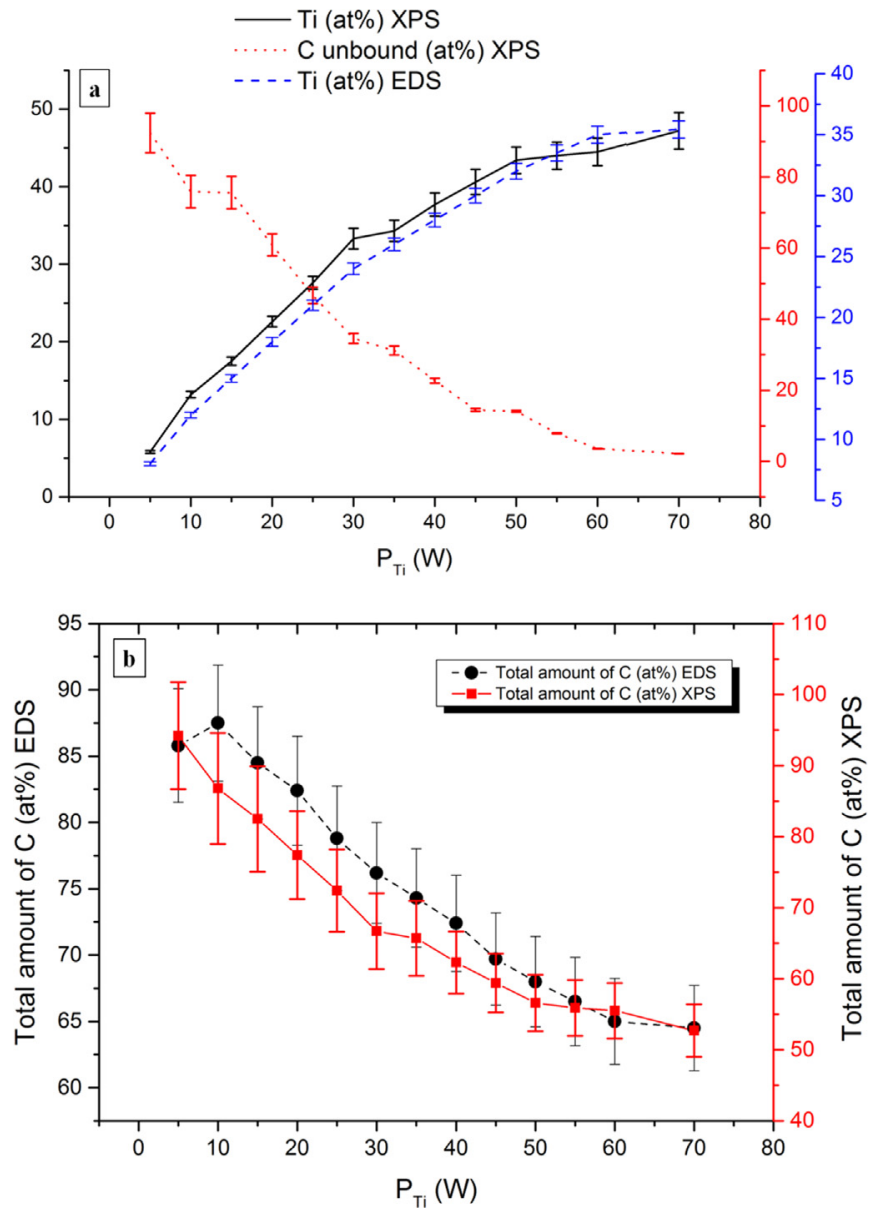

Fig. 2. (a) The Ti content of the $\mathrm{TiC} / \mathrm{a}: \mathrm{C}$ thin films measured by different methods (EDS and XPS) and the unbound (=amorphous) $C$ content depending on the Ti target power. (b) The comparison of the total amount of $\mathrm{C}$ by XPS and by EDS depending on the Ti target power.

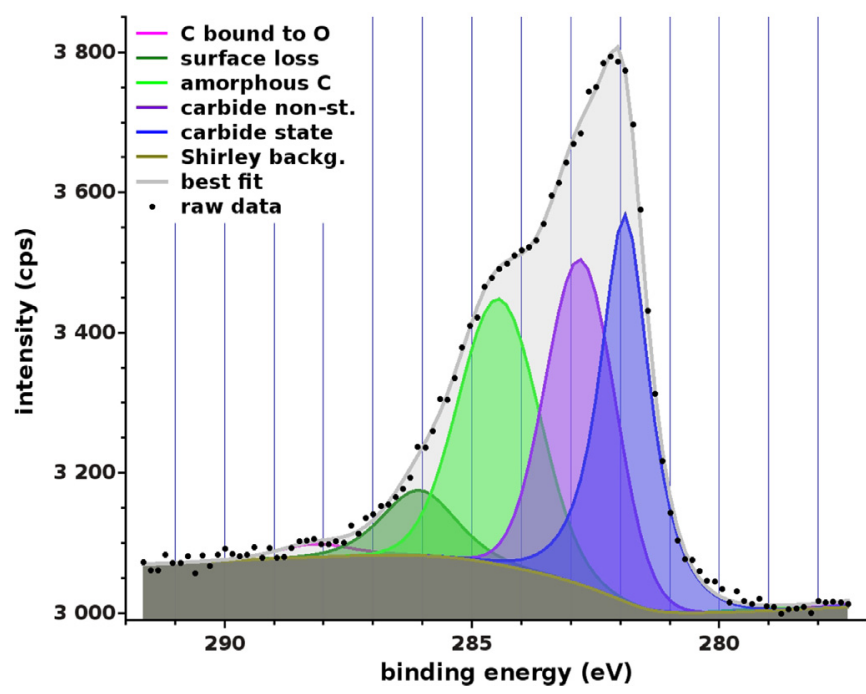

Fig. 3. Decomposed $C$ 1s line from XPS spectra of the TiC/a: $C$ thin nanocomposite film prepared at $40 \mathrm{~W}$ of Ti target power with $\sim 38 \mathrm{at} \% \mathrm{Ti}$.

(carbide) C was significantly less or nearly the same as that of the Ti but in case of this sample it is reversed (Fig. 2a). This result is proven by the appearance of the non-stoichiometric carbide peak in Fig. 3 which is the XPS spectrum of the TiC/a:C nanocomposite thin film in question.
The film prepared at room temperature and $40 \mathrm{~W}$ of Ti target power is found to contain $\sim 38$ at\% Ti by XPS and $\sim 30$ at\% Ti by EDS at the same time. These values are nearly the same within the margin of error (Fig. 2a). This difference is suggested to be due to the difficulties of the $C$ analysis.

The mechanical properties of the thin films were demonstrated to vary greatly with their structure which is described with their chemical composition. As it was mentioned in Section 4, our nanoindentation measurements were slightly influenced by the oxidized Si substrate. However, the contribution of the TiC/a:C films can always be identified on the measured $\mathrm{H}$ and $\mathrm{E}$ curves. This is demonstrated in Fig. 4, where the $\mathrm{H}(a)$ and $\mathrm{E}(b)$ of the substrate are compared to those of the $\mathrm{TiC} / \mathrm{a}: \mathrm{C}$ sample containing $\sim 38$ at\% Ti.

The $\mathrm{H}$ and the $\mathrm{E}$ of $\mathrm{C}-\mathrm{Ti}$ nanocomposite thin films showed a distinct variation depending on titanium content as illustrated in Fig. 5. Namely, the $\mathrm{H}$ and $\mathrm{E}$ values are minimal at the lowest $\mathrm{Ti}$ contents between $\sim 6$ and $\sim 18$ at\%, due to the completely amorphous structure. TiC nanocrystals show up embedded in an a:C matrix at $\sim 18$ at\% Ti. The size of the TiC nanocrystals increases $(\sim 2-8 \mathrm{~nm})$ and the thickness of the a:C layer decreases $(\sim 10$ $3 \mathrm{~nm}$ ) with the increasing amount of Ti until 34 at\%. This results in continuously growing $\mathrm{H}$ and $\mathrm{E}$ values. The Ti content between $\sim 34$ and 41 at\% yields to TiC grains of $8-16 \mathrm{~nm}$ embedded in $2-3 \mathrm{~nm}$ thin amorphous matrix provides the maximal $\mathrm{H}$ and $\mathrm{E}$. These are the most suitable compositions in terms of the mechanical properties. The further increase of the Ti content (41-45 at\%) causes decreasing $\mathrm{H}$ and $\mathrm{E}$. This can be explained as follows: the amount of the $C$ is not enough to develop a fully continuous a: $C$ matrix that leads to the formation of boundaries between TiC grains. This way, the atomic sliding of the $\mathrm{TiC}-\mathrm{TiC}$ grain boundaries becomes possible. Finally, at $\sim 47 \mathrm{at} \% \mathrm{Ti}$ content, the a:C phase disappears, a polycrystalline TiC film forms with grain size of $14-26 \mathrm{~nm}$. Here, the fraction of the grain boundary atoms decreases due to the larger grain size. That refers to the reverse Hall-Petch effect, thus $\mathrm{H}$ and $\mathrm{E}$ increases again. It is worth to mention, that these explanations above are based on the following: In the case of a twophase system when the crystallite size is small (typically less than $10 \mathrm{~nm}$ ), the nanocomposites can be classified depending on the nature of the amorphous phase [31]. Furthermore, the Hall-Petchlike effects are valid in the case of one-phase polycrystalline thin films.

The $\mathrm{H} / \mathrm{E}$ ratio is introduced to describe the failure mechanism of the materials, while the $\mathrm{H}^{3} / \mathrm{E}^{2}$ ratio gives information of the resistance of the material to plastic deformation. In addition, the tribological behavior of this type of coatings can be determined by the measured values of $\mathrm{H}$ and $\mathrm{E}$ [32]. The values of the $\mathrm{H} / \mathrm{E}, \mathrm{H}^{3} / \mathrm{E}^{2}$ and coefficient of friction $(\mathrm{CoF}, \mu)$ are summarized in Fig. 6. The $\mathrm{H} /$ $\mathrm{E}$ ratio close to 0.1 indicates that the deformation of the nanocomposites arises mainly from elastic deformation of the $\mathrm{C}$ matrix resulting in good wear-resistant properties of the thin films $[33,34]$. The higher the $\mathrm{H}^{3} / \mathrm{E}^{2}$ ratio is the higher is the resistance of the film to plastic deformation, stated by Musil et al. [32].

Our film prepared at $40 \mathrm{~W}$ of Ti power ( $\sim 30$ at\% Ti by EDS) had the highest $\mathrm{H}$ of $\sim 26 \mathrm{GPa}$ and the highest $\mathrm{E}$ of $\sim 220 \mathrm{GPa}$ giving $\mathrm{H} /$ E ratio of $\sim 0.12$ and $\mathrm{H}^{3} / \mathrm{E}^{2}$ ratio of $\sim 0.4 \mathrm{GPa}$ as it is seen in Fig. $6 \mathrm{a}$. This $\mathrm{H}^{3} / \mathrm{E}^{2}$ value was compared to the results of Sedláčková et al. [35], Musil et al. [32], and Martínez et al. [36]. Sedlácková et al. obtained $\mathrm{H}^{3} / \mathrm{E}^{2}=0.14 \mathrm{GPa}$ in the case of $\mathrm{C}$-Ti thin film deposited at $200{ }^{\circ} \mathrm{C}\left(\sim 20\right.$ at\% $\mathrm{Ti}$ by EDS), Martínez et al. found $\mathrm{H}^{3} / \mathrm{E}^{2}=0.31 \mathrm{GPa}$ at their sample of maximal hardness (preparation at $75-85^{\circ} \mathrm{C}$ ), while Musil et al. measured $\mathrm{H}^{3} / \mathrm{E}^{2}=0.34 \mathrm{GPa}$ for their sample fabricated at room temperature. In this regard, a better result $\left(\mathrm{H}^{3}\right)$ $\mathrm{E}^{2}=0.37 \mathrm{GPa}$ ) was achieved in our current work also at room temperature.

The coefficient of friction $(\mathrm{CoF}, \mu)$ of $\mathrm{TiC} / \mathrm{a}: \mathrm{C}$ nanocomposite 

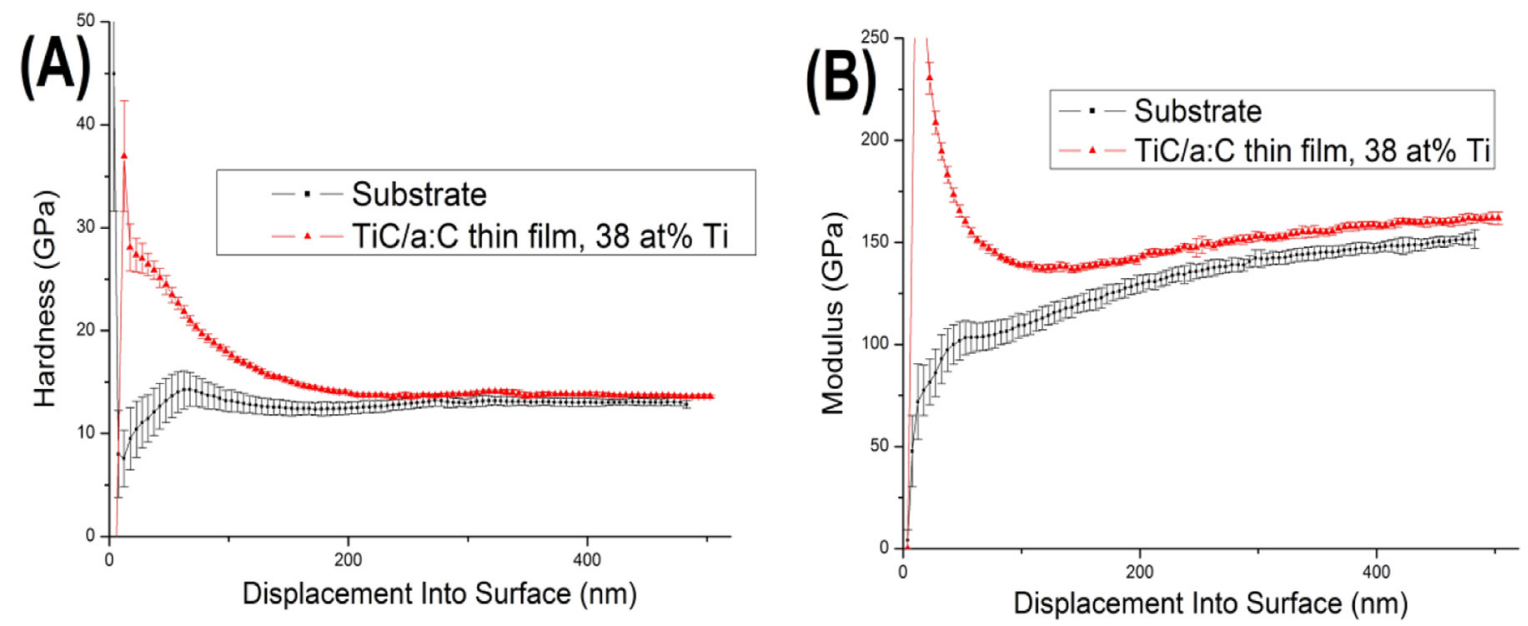

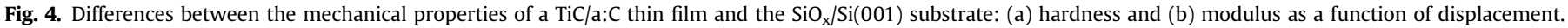

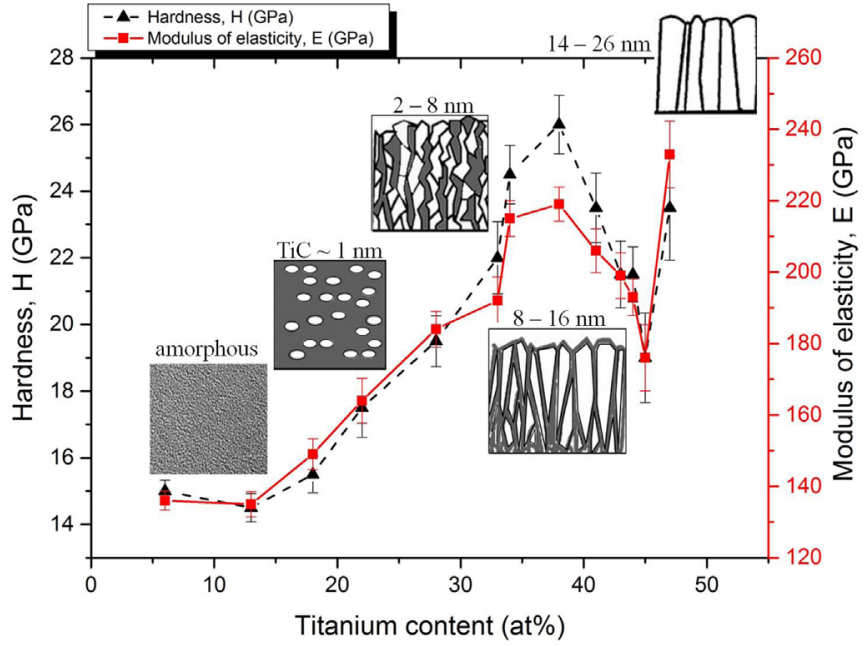

Fig. 5. The measured values of the mechanical characteristics ( $\mathrm{H}$ and $\mathrm{E}$ ) of the $\mathrm{TiC}$ a:C thin films depending on Ti content.

thin films are largely determined by the concentration of titanium and carbon as well. The CoF of our films is depicted depending on the $\mathrm{Ti}$ content in Fig. $6 \mathrm{~b}$. The maximum value of $\mu=0.441$ was found at 41 at\% $\mathrm{Ti}$ concentration, while the CoF of the most suitable composition $(\sim 38$ at\% $\mathrm{Ti})$ is $\mu=0.268$. It is to mention that the CoF of the oxidized Si substrate was found to be $\mu=0.58$. When the Ti concentration is between $\sim 6$ and 33 at\% the friction coefficient values change between 0.087 and 0.156 which values that can be explained by the self-lubrication behavior of a:C phase $[38,39]$. Furthermore, when the Ti concentration exceeds $\sim 34$ at\%, the friction coefficient values change between 0.23 (cf. 0.24 obtained in [4]) and 0.441. These values are corresponding to the friction coefficient of carbon-metal nanocomposites [5,6,9,40,41].

It is worth to mention that in the work of Hu et al. [37] similar trends of hardness, elasticity and CoF values depending on the elemental composition were presented.

\section{Conclusions}

In this work, TiC/a:C nanocomposite thin film with different compositions were deposited by DC magnetron sputtering at room temperature in argon atmosphere onto $\mathrm{SiO}_{\mathrm{x}} / \mathrm{Si}(001)$ substrates for examination and understanding of structural behavior versus mechanical properties of the films. The XPS and TEM
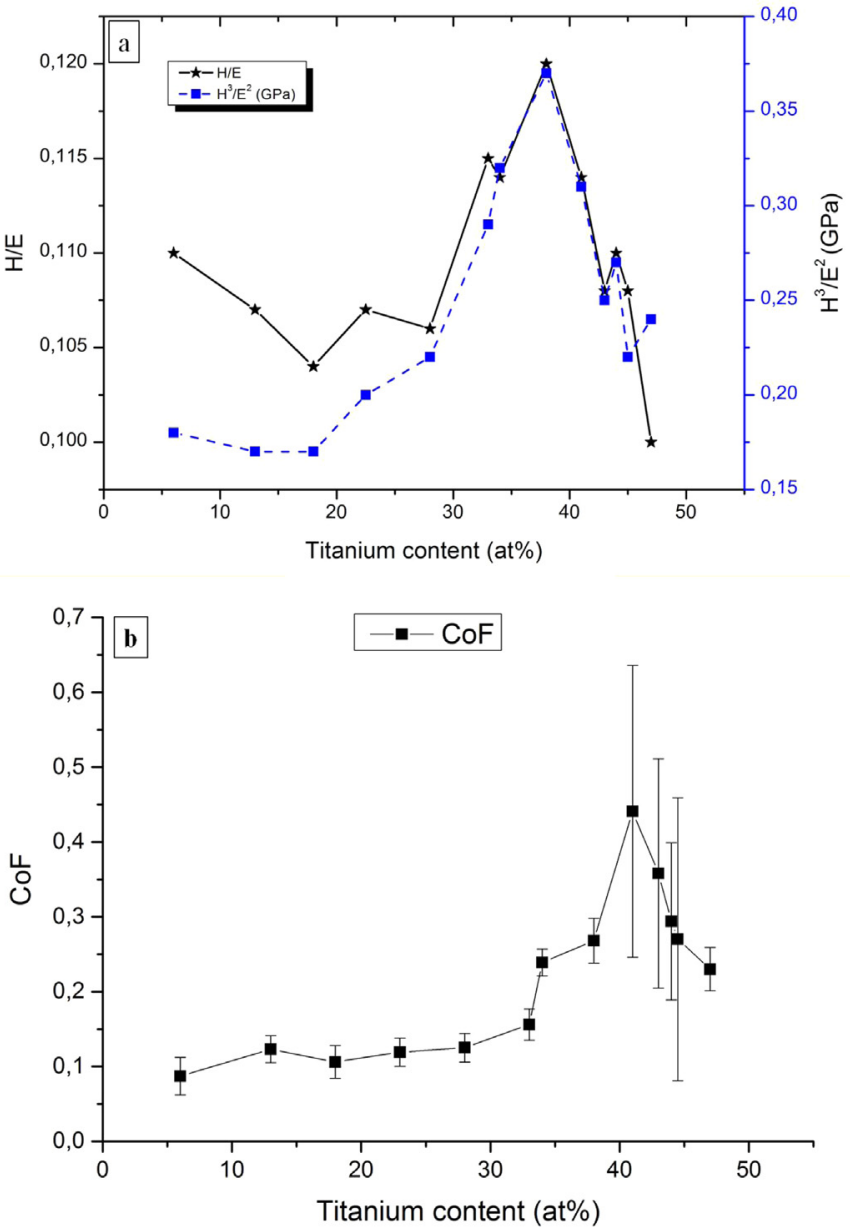

Fig. 6. (a) Comparison of the $\mathrm{H} / \mathrm{E}$ and $\mathrm{H}^{3} / \mathrm{E}^{2}$ values depending on the titanium content and (b) the CoF values of the $\mathrm{TiC} / \mathrm{a}: \mathrm{C}$ thin films with different content of $\mathrm{Ti}$ against $\mathrm{Si}_{3} \mathrm{~N}_{4}$ ball $(5 \mathrm{~mm}, 2 \mathrm{~N}, 3000$ cycle) in ambient air.

measurements confirmed the inverse change of the a:C and carbide phases. Namely, as the Ti content increased from $\sim 6$ at\% to $\sim 47$ at\%, the thickness of the amorphous carbon matrix decreased from $10 \mathrm{~nm}$ to $1-2 \mathrm{~nm}$ and the size of the TiC nanocrystals grew from $\sim 0.5 \mathrm{~nm}$ to $26 \mathrm{~nm}$. The first presence of the fcc TiC nanocrystals, confirmed by SAED, was observed at $\sim 18$ at\% Ti content.

The results of XPS, EDS and TEM are in a good agreement with the equilibrium macro C-Ti phase diagram [30]. Even at the lowest 
total concentration of C $(52.7 \pm 7$ at\%) with the highest concentration of $\mathrm{Ti}(47.3 \pm 5$ at $\%$ ), only the TiC phase was detected. In our case the amorphous carbon was detected at room temperature that has not gone through to a graphitization process.

$\mathrm{H}$ of $\sim 26 \mathrm{GPa}$ and $\mathrm{E}$ of $\sim 220 \mathrm{GPa}$ with $\mu$ of $\sim 0.268$ was observed in case of the film prepared at $\sim 38$ at\% Ti content which consisted of 4-10 nm width TiC columns separated by 2-3 nm thin a:C layers. The $\mathrm{H}^{3} / \mathrm{E}^{2}$ ratio was $\sim 0.4 \mathrm{GPa}$ that predicts high resistance to plastic deformation of the C-Ti nanocomposites beside great wear-resistant properties (H/E of $\sim 0.12$ ). Overall, a TiC/a:C thin film with $\sim 20$ at\% a:C and $\sim 40$ at\% Ti contents would be a suitable choice for a protective nanocomposite coating in terms of the mechanical properties.

\section{Acknowledgments}

Nikolett Oláh thanks to Young Research Fellowship of Hungarian Academy of Sciences (FIKU) for the support and to Levente Illés for the EDS measurements.

\section{References}

[1] S. Kadlec, J. Musil, V. Valvoda, W.-D. Münz, H. Petersein, J. Schroeder, TiN films grown by reactive magnetron sputtering with enhanced ionization at low discharge pressures, Vacuum 41 (1990) 2233-2238.

[2] P. Souček, T. Schmidtová, L. Zábranský, V. Buršíková, P. Vašina, O. Caha, M. Jílek, A. El Mel, P.-Y. Tessier, J. Schäfer, J. Buršík, V. Peřina, R. Mikšová, Evaluation of composition, mechanical properties and structure of nc-TiC/a-C:H coatings prepared by balanced magnetron sputtering, Surf. Coat. Technol. 211 (2012) $111-116$.

[3] K.P. Shaha, Y.T. Pei, D. Martínez-Martínez, J.C. Sanchez-Lopez, J.Th.M. De Hosson, Effect of process parameters on mechanical and tribological performance of pulsed-DC sputtered TiC/a-C:H nanocomposite films, Surf. Coat. Technol. 205 (2010) 2633-2642.

[4] A.G. Kahrizsangi, S.F.K. Bozorg, Microstructure and mechanical properties of steel/TiC nano-composite surface layer produced by friction stir processing, Surf. Coat. Technol. 209 (2012) 15-22.

[5] D. Martínez-Martínez, C. López-Cartes, A. Fernández, J.C. Sánchez-López, Comparative performance of nanocomposite coatings of TiC or TiN dispersed in a-C matrixes, Surf. Coat. Technol. 203 (2008) 756-760.

[6] Y.T. Pei, D. Galvan, J.Th.M. De Hosson, A. Cavaleiro, Nanostructured TiC/a-C coatings for low friction and wear resistant applications, Surf. Coat. Technol. 198 (2005) 44-50.

[7] I. Petrov, P.B. Barna, L. Hultman, R.J. Greene, Microstructural evolution during film growth, J. Vac. Sci. Technol. A21 (2003) 117-127.

[8] D. Martínez-Martínez, C. López-Cartes, A. Fernández, J.C. Sánchez-López, Influence of the microstrucutre on the mechanical and tribological behavior of TiC/a-C nanocomposite coatings, Thin Solid Films 517 (2009) 1662-1671.

[9] N. Kumar, G. Natarajan, R. Dumpala, R. Pandian, A. Bahuguna, S.K. Srivastava, T. R. Ravindran, S. Rajagopalan, S. Dash, A.K. Tyagi, M.S.R. Rao, Microstructure and phase composition dependent tribological properties of TiC/a-C nanocomposite thin films, Surf. Coat. Technol. 258 (2014) 557-565.

[10] P. Souček, T. Schmidtová, L. Zábranský, V. Buršíková, P. Vašina, O. Caha, J. Buršík, V. Peřina, R. Mikšová, Y.T. Pei, J.Th.M. De Hosson, On the control of deposition process for enhanced mechanical properties of nc-TiC/a-C:H coatings with DC magnetron sputtering at low or high ion flux, Surf. Coat. Technol. $255(2014) 8-14$.

[11] P. Yuan, D. Gu, D. Dai, Particulate migration behavior and its mechanism during selective laser melting of TiC reinforced $\mathrm{Al}$ matrix nanocomposites, Mater. Des. 82 (2015) 46-55.

[12] D. Gu, H. Wang, F. Chang, D. Dai, P. Yuan, Y.-C. Hagedorn, W. Meiners, Selective Laser Melting Additive Manufacturing of TiC/AlSi10Mg Bulk-form Nanocomposites with Tailored Microstructures and Properties, Phys. Procedia 56 (2014) 108-116.

[13] R. Kumar, A.K. Chaubey, S. Bathula, B.B. Jha, A. Dhar, Synthesis and characterization of Al2O3-TiC nano-composite by spark plasma sintering, Int. J. Refract. Met. Hard Mater. 54 (2016) 304-308.

[14] M. Zhou, P.D.D. Rodrigo, X. Wang, J. Hu, S. Dong, Y.-B. Cheng, A novel approach for preparation of dense TiC-SiC nanocomposites by sol-gel infiltration and spark plasma sintering, J. Eur. Ceram. Soc. 34 (2014) 1949-1954.

[15] W. Li, F. Li-hong, G. Jian-hong, First-principles study of TiC(110) surface, Trans. Nonferrous Met. Soc. China 22 (2012) 170-174.
[16] L.M. Liu, S.Q. Wang, H.Q. Ye, First-principle study of the polar TiC/Ti interface, J. Mater. Sci. Technol. 19 (2003) 540-544.

[17] R. Ahuja, O. Eriksson, J.M. Wills, B. Johansson, Structural, elastic, and highpressure properties of cubic TiC, TiN, and TiO, Phys. Rev. B 53 (1996) 3072.

[18] M. Stüber, H. Leiste, S. Ulrich, H. Holleck, D. Schild, Microstructure and properties of low friction TiC-C nanocomposite coatings deposited by magnetron sputtering, Surf. Coat. Technol. 150 (2002) 218-226.

[19] A. Mani, P. Aubert, F. Mercier, H. Khodja, C. Berthier, P. Houdy, Effects of residual stress on the mechanical and structural properties of TiC thin films grown by RF sputtering, Surf. Coat. Technol. 194 (2005) 190-195.

[20] A. Zouina, A. Djafer, N. Saoula, N. Madaoui, A. Zerizer, Deposition and characterization of titanium carbide thin films by magnetron sputtering using Ti and TiC targets, Appl. Surf. Sci. 312 (2014) 57-62.

[21] A.A. El Mel, B. Angleraud, E. Gautron, A. Granier, P.Y. Tessier, Microstructure and composition of TiC/a-C:H nanocomposite thin films deposited by a hybrid IPVD/PECVD process, Surf. Coat. Technol. 204 (2010) 1880-1883.

[22] Y. Wang, J. Wang, G. Zhang, L. Wang, P. Yan, Microstructure and tribology of $\mathrm{TiC}(\mathrm{Ag}) / \mathrm{a}-\mathrm{C}: \mathrm{H}$ nanocomposite coatings deposited by unbalanced magnetron sputtering, Surf. Coat. Technol. 206 (2012) 3299-3308.

[23] G.K. Meenashisundaram, M. Gupta, Synthesis and characterization of high performance low volume fraction TiC reinforced Mg Nanocomposites targeting Biocompatible/Structural Applications, Mater. Sci. Eng. A 627 (2015) 306-315.

[24] W.J. Meng, R.C. Tittsworth, L.E. Rehn, Mechanical properties and microstructure of TiC/amorphous hydrocarbon nanocomposite coatings, Thin Solid Films 377/378 (2000) 222-232.

[25] D.V. Shtansky, N.A. Gloushankova, I.A. Bashkova, M.I. Petrzhik, A.N. Sheveiko, $\mathrm{Ph}$ V. Kiryukhantsev-Korneev, et al., Multifunctional biocompatible nanostructured coatings for load-bearing implants, Surf. Coat. Technol. 201 (2006) $4111-4118$.

[26] N. Oláh, M. Veres, A. Sulyok, M. Menyhárd, J. Gubicza, K. Balázsi, Examination of nanocrystalline TiC/amorphous C deposited thin films, J. Eur. Ceram. Soc. 34 (2014) 3421-3425.

27] N. Oláh, Zs Fogarassy, M. Furkó, Cs Balázsi, K. Balázsi, Sputtered nanocrystalline ceramic TiC/amorphous C thin films as potential materials for medical applications, Ceram. Int. 41 (2015) 5863-5871.

[28] W.C. Oliver, G.M. Pharr, An improved technique for determining hardness and elastic modulus using load and displacement sensing indentation experiments, J. Mater. Res. 7 (1992) 1564-1583.

[29] W.C. Oliver, G.M. Pharr, Measurement of hardness and elastic modulus by instrumented indentation: advances in understanding and refinements to methodology, J. Mater. Res. 19 (2004) 3-20.

[30] T.B. Massalski (ed), Binary Alloy Phase Diagrams, second ed., 3 volumes, ASM International, 1990.

[31] J. Musil, J. Vlček, Magnetron sputtering of hard nanocomposite coatings and their properties, Surf. Coat. Technol. 142 (2001) 557-566.

[32] J. Musil, P. Novák, R. Čerstvý, Z. Soukup, Tribological and mechanical properties of nanocrystalline-TiC/a-C nanocomposite thin films, J. Vac. Sci. Technol. A 28 (2) (2010) 244-249.

[33] Y.T. Pei, D. Galvan, J.Th.M. De Hosson, C. Strondl, Advanced TiC/a-C:H nanocomposite coatings deposited by magnetron sputtering, J. Eur. Ceram. Soc. 26 (2006) 565-570.

[34] K. Sedláčkova, Zs Czigány, T. Ujvári, I. Bertóti, R. Grasin, Gy.J. Kovács, G. Radnóczi, The effect of the carbon matrix on the mechanical properties of nanocomposite films containing nickel nanoparticles, Nanotechnology 18 (2007) 445604 (5pp).

[35] K. Sedláčková, R. Grasin, G. Radnóczi, Carbon-metal (Ni-Ti) nanocomposite films as protective coatings, in: L.M. Krause (Ed.), New Research on Nanocomposites, Nova Pls, New York, 2008, pp. 223-246.

[36] D. Martínez-Martínez, C. López-Cartes, A. Fernández, J.C. Sánchez-López, Influence of the microstrucutre on the mechanical and tribological behavior of TiC/a-C nanocomposite coatings, Thin Solid Films 517 (2009) 1662-1671.

[37] Y. Hu, L. Li, X. Cai, Q. Chen, P.K. Chu, Mechanical and tribological properties of TiC/amorphous hydrogenated carbon composite coatings fabricated by DC magnetron sputtering with and without sample bias, Diam. Relat. Mater. 16 (2007) 181-186.

[38] Q.N. Meng, M. Wen, F. Mao, N. Nedfors, U. Jansson, W.T. Zheng, Deposition and characterization of reactive magnetron sputtered zirconium carbide films, Surf. Coat. Technol. 232 (2013) 876-883.

[39] P. Souček, T. Schmidtová, V. Buršíková, P. Vašina, Y.T. Pei, J.Th.M. De Hosson, O. Caha, V. Peřina, R. Mikšová, P. Malinský, Tribological properties of nc-Tic/aC:H coatings prepared by magnetron sputtering at low and high ion bombardment of the growing film, Surf. Coat. Technol. 241 (2014) 64-73.

[40] S. Louring, N.D. Madsen, M. Sillassen, A.N. Berthelsen, B.H. Christensen, K. P. Almtoft, H. Ronkainen, L.P. Nielsen, J. Bøttiger, Microstructural, mechanical and tribological analysis of nanocomposite $\mathrm{Ti}-\mathrm{C}-\mathrm{N}$ coatings deposited by industrial-scale DC magnetron sputtering, Surf. Coat. Technol. 245 (2014) 40-48.

[41] T.-H. Fang, S.-R. Jian, D.-S. Chuu, Nanomechanical properties of TiC, TiN and TiCN thin films using scanning probe microscopy and nanoindentation, Appl. Surf. Sci. 228 (2004) 365-372. 